\title{
The average-cost formulation of lot sizing models and inventory carrying charges: a technical note
}

\author{
Davide Castellano ${ }^{1}$ [ $\cdot$ Christoph H. Glock ${ }^{2}$
}

Received: 8 December 2020 / Revised: 24 February 2021 / Accepted: 2 April 2021 / Published online: 14 April 2021

(C) The Author(s) 2021

\begin{abstract}
It is generally recognised that the present-value criterion should be preferred to the average-cost formulation in developing lot sizing models. Despite the advantages of the present-value measure, average-cost lot sizing models are far more widely applied. Because of the nature of the average-cost formulation, inventory carrying costs are evaluated according to a lookback approach, relying on historical values. In this regard, a general misconception in the inventory management literature concerned with average-cost models is that the unit stockholding cost rate should be established considering fixed warehouse costs, which are costs that are, in the short term, independent of the inventory level. This paper develops arguments supporting our belief that inventory carrying charges used in lot sizing models should take into account only those costs varying with the inventory level in the warehouse, and that considering fixed warehouse costs leads to pitfalls when making inventory replenishment decisions. To this aim, we first present an analytical treatment based on the classical Economic Order Quantity (EOQ) model, as its full analytical tractability permits us to better discuss the problem we are interested in. Finally, we present numerical experiments to assess the effect of the correct procedure to establish the unit stockholding cost rate on inventory management decisions. These experiments are performed considering warehouse costs taken from some industrial case studies presented in the literature.
\end{abstract}

Keywords Inventory $\cdot$ Stockholding cost $\cdot$ Warehouse $\cdot$ Economic order quantity $\cdot$ Lot sizing $\cdot$ Average cost

\section{Introduction}

The management of inventories is a critical issue in almost every company. Inventories are fundamental to the vitality of firms and to the health of entire modern economies (Silver et al. 2017). The U.S. Census Bureau (2021) reports that companies in the United States from the industrial, retailing and merchant wholesale sectors held, on average, more than $\$ 1.7$ trillion $\left(10^{12}\right)$ on stock between December 2010 and December 2020, which illustrates the enormous impact inventory management has also on an economic level. There are a number of reasons why organizations hold inventories.

Davide Castellano

davide.castellano@unina.it

1 Department of Chemical, Materials, and Industrial Production Engineering, Università degli Studi di Napoli "Federico II", Piazzale V. Tecchio 80, 80125 Napoli, Italy

2 Department of Law and Economics, Technical University of Darmstadt, Hochschulstraße 1, 64289 Darmstadt, Germany
We cite, for example, the possibility to exploit economies of scale, the need to cope with uncertainties in supply and demand, and the opportunity of speculation, among others (Nahmias 2013).

Careful inventory management is crucial to a firm's strategic viability (Zipkin 2000). Companies that use scientific inventory management methods have a significant competitive advantage in the marketplace (Nahmias 2013). These methods are needed to answer two fundamental questions related to inventories: (1) When should an order be placed? And (2) how much should be ordered?

A number of mathematical models embodying specific operating doctrines have been developed over the years to address the previous questions - the Economic Order Quantity (EOQ) model by Harris (1913) was the first attempt in this regard. These (lot sizing) models require that a cost (or a profit) function be identified, including all and only those costs incurred in operating an inventory system and that are affected by the operating doctrine itself (Hadley and Whitin 1963). 
Virtually all inventory-related costs can be placed into one of three categories: ordering cost, holding cost, and penalty cost (Nahmias 2013). These costs can briefly be characterized as follows:

- The ordering cost depends on the amount of inventory that is ordered or produced, and, in general, it has two components: a fixed component and a variable component that depends on the ordered/produced amount.

- The holding cost, according to its classical definition, includes all costs that are proportional to the amount of inventory physically on hand at any point in time, and it is characterised by a number of different cost items (further details will be given later on in the paper).

- The penalty cost is the cost related to not having sufficient stock on hand to satisfy a demand as it occurs, and different interpretations of this cost are given depending on whether an unmet demand is lost or backordered.

Quantifying these cost factors is very difficult. Cost measurement is, in practice, a problem that has not been conclusively solved yet (Silver et al. 2017).

Two alternative criteria can be used for measuring costs and revenues in lot sizing models (Zipkin 2000): (i) the present-value (or discounted-cost) and (ii) the average-cost approach. The inventory management literature recognises that the present-value formulation is, in general, more appropriate to make inventory replenishment decisions (see, e.g., Andriolo et al. 2014; Grubbström and Thorstenson 1986; Teunter et al. 2000). This evaluation is based, in particular, on the way these two approaches estimate the inventory holding costs. Average-cost models measure these costs adopting a look-back perspective. As observed by Zipkin (2000), this means that the unit stockholding cost rate is an average value extrapolated from historical data, and it is therefore based on past holding costs resulting from past order quantities. A further issue is that past data also includes historical costs of shared resources across items, mixing variable and fixed costs together. The present-value criterion, as a look-forward methodology, overcomes the previously discussed issues arising from the average-cost measure. In fact, it accounts for the timing of payments and permits to disclose what values to ascribe to products at different stages of the production and inventory processes (see, e.g., Grubbström 1980; Grubbström and Thorstenson 1986). As a result, the present-value formulation better reflects the economic impact of alternative inventory policies (Zipkin 2000).

Despite the advantages of the present-value measure, average-cost lot sizing models are far more widely applied (Andriolo et al. 2014; Teunter et al. 2000; Zipkin 2000). This may be due to several reasons (Zipkin 2000): (1) the average-cost formulation was developed earlier, (2) it is built on concrete, physical measures, such as the average inventory, and (3) an explicit formula is available for several cases (see, e.g., the classical EOQ model). Averagecost models are also regarded as an approximation of their counterpart developed according to the present-value criterion, and the approximation is reasonably accurate in most cases of practical interest (Zipkin 2000).

Since, as previously observed, average-cost lot sizing models are quite attractive to practitioners and scholars, research efforts aiming to improve the calculation of the actual cost parameters for this class of models are undoubtedly necessary. In this regard, the evaluation of the inventory carrying charges needs particular attention.

Inventory management textbooks provide general guidelines about how to calculate the unit stockholding cost rate according to the traditional procedure characterising the average-cost formulation of lot sizing models (see, e.g., Hadley and Whitin 1963; Silver et al. 2017). To the best of our knowledge, the only paper that proposes a detailed procedure for establishing this cost parameter, in a practical context, is the one of Azzi et al. (2014). They presented a methodological framework to calculate the stockholding cost rate based on approaches used by industrial managers in practice. To compute the stockholding cost rate, the authors conducted case studies involving ten industrial companies. The participants were assigned to two equal-sized groups with each group using a specific type of warehousing system: a mainly manual or a mainly automated/automatic warehouse. Each group was then involved in discussions and brainstorming activities aiming to understand how the unit stockholding cost rate is calculated by the managers, in the respective contexts represented by the two groups. As a result of the brainstorming sessions with the two groups, the authors proposed two different methodologies to compute the inventory carrying cost rate each pertaining to one of the two warehousing system categories considered in their work: approach A deals with manual warehouses, while approach B concerns automated/automatic warehouses.

The methodology Azzi et al. (2014) proposed is generally in line with the recommendations given in classical inventory management textbooks that explicitly state that the costs of warehouses should be included in establishing the inventory carrying costs (see Hartmann 2002, p. 397; Hadley and Whitin 1963, p. 13; Johnson and Montgomery 1974, p. 19; Relph and Milner 2015, p. 21; Silver et al. 2017, p. 41; Waters 1992, p. 19). We argue that warehouse costs are fixed and independent of the inventory level in the short term, and that including these (and other costs that do not depend on the inventory level) in computing the inventory carrying costs leads to pitfalls when making inventory replenishment decisions (e.g., ordering more often, or a smaller quantity, than actually required by the true optimal decision). 
In spite of the importance of the topic, to the best of the authors' knowledge, this issue has never been discussed in the international inventory management literature dealing with the average-cost formulation. We only identified a few German textbooks that briefly argued that (fixed) costs that do not depend on the lot size (such as warehouse costs) should not be included in establishing the inventory carrying costs, however without providing a more detailed discussion of this topic (see, e.g., Bogaschewsky 1996, p. 1143, Buscher et al. 2010, p. 158; Glock 2014, p. 90, Hahn and Laßmann 1999, p. 358). ${ }^{1}$

The purpose of this paper is twofold. Firstly, we explain why traditional procedures for calculating the unit stockholding cost rate, according to the traditional average-cost measure, used in various textbooks and in the work of Azzi et al. (2014) may distort the inventory control decision. Secondly, we show how the conventional procedure should be modified, taking into account the methodology proposed by Azzi et al. (2014), which seems to be the most comprehensive one currently available in the literature.

The remainder of the paper is organized as follows. In Sect. 2, we use analytical arguments to show how the traditional procedure to establish the unit stockholding cost rate can distort inventory control decisions taking into reference the classical EOQ model. In Sect. 3, we evaluate an adjusted calculation procedure for the unit stockholding cost rate in numerical experiments. Finally, Sect. 4 concludes the paper.

\section{Theoretical analysis}

To better illustrate the issue we want to point out, consider the simplest deterministic lot sizing model, i.e., the classical average-cost EOQ model, in the following. This model that was originally proposed by Harris (1913) aims to find an optimal order quantity that minimizes the sum of inventory carrying and ordering costs. Extensions of Harris' inventory model are reviewed, e.g., in the works of Andriolo et al. (2014) and Glock et al. (2014), which present, respectively, a discussion of the evolution of lot sizing models, starting from the basic one developed by Harris in 1913, and a survey of literature reviews, i.e., a tertiary study, in the context of lot sizing. Our focus is on an item stocked in a manual warehouse, but a conceptually similar analysis would result if we considered an item stocked in an automated/automatic warehouse. Note that we consider the classical EOQ model because its full analytical tractability (i.e., the fact that a

\footnotetext{
${ }^{1}$ In a similar line of thought, Adam (2001), p. 478, argued that the setup cost used in lot sizing models should only include cost components that depend on the number of setups. Salaries that have to be paid to workers independent of the number of setups performed should not be included in establishing the setup costs.
}

closed-form expression is available both for the optimal lot size and for the minimum cost) permits us to better discuss the problem we are interested in. Although the analytical laws we develop are specific for the EOQ model, our arguments are clearly applicable to any inventory control model, and the outcomes of our analysis are plausibly of general validity.

Let $Q, D, A$, and $v$ be the lot size, the demand per year, the ordering cost per order, and the unit value, respectively. According to approach A presented by Azzi et al. (2014), we evaluate the carrying charge $r$, i.e., the cost in Euros of carrying one Euro of inventory for one year, as follows:

$r=\frac{\sum_{i=1}^{N} \mathfrak{c}_{i}}{\mathfrak{V}}+\epsilon$

where $\mathfrak{C}_{i}$ is the $i$ th cost factor [ $€ /$ year], $\mathfrak{B}$ is the mean inventory investment [ $€], \epsilon$ is the annual opportunity cost, and $N$ is the total number of cost factors [note that Azzi et al. (2014) identify 20 cost factors for approach A, i.e., $N=20$ ]. To discuss the issue in the methodology proposed by Azzi et al. (2014), consider, just as an example, the cost term related to the annual building amortization charge, and let $\mathfrak{夭}_{i_{1}}$ be this cost term among the $N$ factors (a different fixed cost, independent of the inventory level in the warehouse, may be considered; $\mathfrak{c}_{i_{1}}$ may also be regarded as the sum of all these fixed costs). We rewrite Eq. (1) as follows:

$r=\frac{\mathfrak{c}_{i_{1}}+\sum_{i=1, i \neq i_{1}}^{N} \mathfrak{夭}_{i}}{\mathfrak{D}}+\epsilon$.

The unit stockholding cost rate, $h$ [€/unit/year], of the item under consideration is thus given by

$h=v r=v\left(\frac{\mathfrak{夭}_{i_{1}}+\sum_{i=1, i \neq i_{1}}^{N} \mathfrak{C}_{i}}{\mathfrak{V}}+\epsilon\right)$.

We can now use the EOQ formula to get the optimal order lot, $Q^{*}$, and the related minimum cost rate, $\mathfrak{K}^{*}[€ /$ year]:

$Q^{*}=\sqrt{\frac{2 A D}{h}}$,

$\mathfrak{\Re}^{*}=\sqrt{2 h A D}$

Assume that the company renovates the warehouse. This will lead to an investment, with consequent depreciation, that impacts the carrying charge, $r$, and the unit stockholding cost rate, $h$, as well if we follow the approach of Azzi et al. (2014). In particular, after this investment was made, we will have a new annual building amortization charge, denoted by $\overline{\mathfrak{夭}}_{i_{1}}$ with $\mathfrak{c}_{i_{1}}<\overline{\mathfrak{C}}_{i_{1}}$. As a result, we will obtain a new carrying charge, $\bar{r}$, and unit stockholding 
cost rate, $\bar{h}$, that evidently are larger than in the initial configuration, i.e., $r<\bar{r}$ and $h<\bar{h}$. The updated optimal lot size and minimum cost rate are then, respectively,

$\bar{Q}^{*}=\sqrt{\frac{2 A D}{\bar{h}}}<Q^{*}$,

$\overline{\mathfrak{\Re}}^{*}=\sqrt{2 \bar{h} A D}>\Re^{*}$.

We observe that the increment in the minimum cost rate is the result of larger optimal ordering cost per year and optimal stockholding cost per year.

One may now want to examine how much the minimum cost rate has increased, as a result of the larger unit stockholding cost rate, which, in turn, originates from the increment in $\mathfrak{c}_{i_{1}}$. We can write $\bar{h}$ as follows:

$$
\begin{aligned}
& \bar{h}=v \bar{r}=v\left(\frac{\overline{\mathfrak{S}}_{i_{1}}+\sum_{i=1, i \neq i_{1}}^{N} \mathfrak{\mathfrak { V }}_{i}}{\mathfrak{V}}+\epsilon\right) \\
& =v\left(\frac{\Delta+\mathfrak{S}_{i_{1}}+\sum_{i=1, i \neq i_{1}}^{N} \mathfrak{S}_{i}}{\mathfrak{V}}+\epsilon\right) \\
& =v\left(\frac{\Delta}{\mathfrak{V}}+\frac{\mathfrak{G}_{i_{1}}+\sum_{i=1, i \neq i_{1}}^{N} \mathfrak{G}_{i}}{\mathfrak{V}}+\epsilon\right) \\
& =v\left(r_{\Delta}+r\right)=h_{\Delta}+h \text {, }
\end{aligned}
$$

where we let $\Delta=\overline{\mathfrak{C}}_{i_{1}}-\mathfrak{\mathfrak { V }}_{i_{1}}, r_{\Delta}=\Delta / \mathfrak{V}$, and $h_{\Delta}=v r_{\Delta}$. We then have:

$\overline{\mathfrak{R}}^{*}=\sqrt{2 \bar{h} A D}=\sqrt{2 A D\left(h_{\Delta}+h\right)}$,

and

$$
\begin{aligned}
\Delta^{*} & =\overline{\mathfrak{\Omega}}^{*}-\mathfrak{\Omega}^{*}=\sqrt{2 \bar{h} A D}-\sqrt{2 h A D} \\
& =\sqrt{2 A D\left(h_{\Delta}+h\right)}-\sqrt{2 A D h} \\
& =\sqrt{2 A D h}\left(\frac{\sqrt{2 A D\left(h_{\Delta}+h\right)}}{\sqrt{2 A D h}}-1\right) \\
& =\sqrt{2 A D h}\left(\sqrt{\frac{h_{\Delta}+h}{h}}-1\right) \\
& =\sqrt{2 A D h}\left(\sqrt{1+\frac{h_{\Delta}}{h}}-1\right) \leq \sqrt{2 A D h_{\Delta}},
\end{aligned}
$$

where the last passage follows from the triangle inequality.
Note that we have $\Delta^{*} \leq \Delta$ or $\Delta^{*}>\Delta$ depending on the specific combination of parameter values. In particular, the equation $\Delta^{*}=\Delta$ has one solution for $\Delta=\Delta_{1}=0$, irrespective of the other parameter values (this is a "trivial" solution), and another (real) solution is obtained for

$$
\Delta=\Delta_{2}=\frac{2 A D v}{\mathfrak{V}}-2 \sqrt{2 A D v\left(\frac{\mathfrak{E}_{i_{1}}+\sum_{i=1, i \neq i_{1}}^{N} \mathfrak{\mathfrak { V }}_{i}}{\mathfrak{V}}+\epsilon\right)}
$$

only if $\Delta_{2}>0$. Then we have $\Delta^{*} \leq \Delta$, for all $\Delta \geq \max \left\{0, \Delta_{2}\right\}$. The property $\Delta^{*} \leq \Delta$ means that increasing $\mathfrak{C}_{i_{1}}$ by $\Delta$ leads to an increment in the minimum cost rate less than $\Delta$.

The fundamental point arising from the previous analysis is that the above model does not adequately account for increments in the fixed, inventory level-independent costs that are included in the calculation of the unit stockholding cost rate, according to the methodology of Azzi et al. (2014). This happens because the nature of these fixed costs is incorrectly addressed by their methodology. In fact, as one can intuitively deduce, these costs are paid independently of the inventory level in the warehouse, and hence they cannot hold any role in establishing the most efficient (or most profitable) inventory policy. For example, the annual building amortization charge, $\mathfrak{c}_{i}$, considered in the previous discussion, is paid every year independently of whether there is stock in the warehouse, or not. As a result, fixed, inventory level-independent costs should be included as a lot-independent cost term in the cost function of the adopted inventory model. We revise the classical average-cost EOQ model accordingly as follows.

Let $\mathcal{N}$ be the set of all cost factors [if we consider approach A of the methodology in Azzi et al (2014), then $\operatorname{card}(\mathcal{N})=N=20$, where $\operatorname{card}(\mathcal{N})$ identifies the cardinality of set $\mathcal{N}$ ]. Let $\mathcal{N}_{1}$ be the set of cost factors that are fixed and independent of the lot size and let $\mathcal{N}_{2}=\mathcal{M} \mathcal{N}_{1}$. The revised carrying charge is

$\widehat{r}=\frac{\sum_{i \in \mathcal{N}_{2}} \mathfrak{G}_{i}}{\mathfrak{V}}+\epsilon$,

and then the revised unit stockholding cost rate is

$\widehat{h}=v \widehat{r}=v\left(\frac{\sum_{i \in \mathcal{N}_{2}} \mathfrak{S}_{i}}{\mathfrak{V}}+\epsilon\right)$.

Note that

$\widehat{h}<h=v\left(\frac{\sum_{i \in \mathcal{N}_{1}} \mathfrak{G}_{i}+\sum_{i \in \mathcal{N}_{2}} \mathfrak{⿰}_{i}}{\mathfrak{V}}+\epsilon\right)$. 
If we let $\mathfrak{S}=\sum_{i \in \mathcal{N}_{1}} \mathfrak{C}_{i}$, i.e., $\mathfrak{C}$ represents the total fixed cost rate, we finally get the following cost rate formulation:

$\widehat{\mathfrak{\Re}}=\widehat{\Re}(Q)=\frac{A D}{Q}+\widehat{h} \frac{Q}{2}+\mathfrak{C}$,

where $\mathfrak{C}$ evidently is a $Q$-independent cost term that is paid once every time unit and that does not affect the optimal inventory policy. The lot $\widehat{Q}^{*}$ minimizing $\widehat{\mathfrak{\Omega}}$ is given by

$\widehat{Q}^{*}=\sqrt{\frac{2 A D}{\hat{h}}}>Q^{*}=\sqrt{\frac{2 A D}{h}}$,

and the corresponding minimum cost is

$\widehat{\Re}^{*}=\sqrt{2 \widehat{h} A D}+\mathfrak{C}$.

Note that nothing can be said a priori regarding the relationship between $\widehat{\mathfrak{\Re}}^{*}$ and $\mathfrak{\Re}^{*}$. The specific combination of parameter values affects the relative position of $\widehat{\mathfrak{\Re}}^{*}$ with respect to $\mathfrak{\Re}^{*}$.

Now, suppose that $\mathfrak{C}$ is increased by a quantity $\Delta$. The updated minimum cost rate is

$\widehat{\Re}^{*}=\sqrt{2 \widehat{h} A D}+\mathfrak{C}+\Delta$.

We thus get

$\Delta^{*}=\sqrt{2 \widehat{h} A D}+\mathfrak{C}+\Delta-(\sqrt{2 \hat{h} A D}+\mathfrak{C})=\Delta$,

In other words, increasing $\mathfrak{C}$ by a quantity $\Delta$ inflates $\widehat{\mathfrak{\Re}}^{*}$ by the same quantity $\Delta$. This behaviour is evidently consistent with the definition (or the nature) of fixed, inventory levelindependent cost.

We now make the following final observation. Consider the case in which fixed, inventory level-independent costs, $\mathfrak{c}$, are excluded by the model. Then, the optimal lot, in this configuration, is exactly $\widehat{Q}^{*}$, as given in Eq. (16), and the corresponding minimum cost rate is

$\tilde{\Re}^{*}=\sqrt{2 \widehat{h} A D}=\widehat{\Re}^{*}-\mathfrak{C}$.

Hence, $\widehat{\mathfrak{K}}^{*}$ is obtained translating $\tilde{\mathfrak{K}}^{*}$, along the cost dimension, by a value $\mathfrak{C}$.

One important contribution of Azzi et al. (2014) is that they decompose the unit stockholding cost rate into a set of potential components depending on the nature of the warehouse, i.e., whether it is manual or automated/automatic. The reader is referred to their Table I, which shows cost structure A that is relevant to a manual warehouse and cost structure B that is relevant to an automated/automatic warehouse. Motivated by the arguments presented in this work regarding the requirement to exclude fixed, inventory level-independent costs from the calculation of the unit stockholding cost rate, the cost structures presented by Azzi et al. (2014) can be sharpened to differentiate fixed costs from variable (i.e., inventory leveldependent) costs. A possible result of this classification is presented in Table 1. This table can thus be used to evaluate the correct unit stockholding cost rate, $\widehat{h}$, and the total fixed cost rate, $\mathfrak{C}$. Note that, depending on the specific context, some costs denoted below as fixed could instead be variable and dependent on the inventory level. For example, insurance fees may depend on the quantity/value stocked and it may be possible to save some energy by reducing lighting in areas of the warehouse not in use. Some of these peculiar cost factors are marked with an asterisk in Table 1.

\section{Numerical experiments}

This section presents numerical examples to investigate the effect of the adjusted procedure to evaluate the unit stockholding cost rate on inventory management decisions. These experiments are carried out considering an item stocked in a manual warehouse whose optimal lot size is obtained through the classical EOQ model.

In this analysis, we consider five different inventory systems, each characterised by specific inventory carrying cost charges. These five inventory systems are those presented by Azzi et al. (2014) in their Table II. To make the comparison as fair as possible, the demand rate, $D$ [quantity unit/year], the ordering cost per order, $A$ [€/order], and the unit value, $v$ [€/quantity unit], are assumed identical for each industrial case. Clearly, this assumption is not realistic, but we think it is appropriate in this context given the goal of the experiments. Moreover, the available data in Azzi et al. (2014) do not include some fundamental parameters of the inventory system, such as the unit value, $v$. In particular, we assume $D=5000$ units/year, $A=€ 250 /$ order, and $v=€ 200 /$ unit. We recall that $\widehat{Q}^{*}$ and $\widehat{\mathfrak{K}}^{*}$ are the optimal lot size and the minimum cost rate for the model with adjusted unit stockholding cost rate, $\widehat{h}$, while $Q^{*}$ and $\mathfrak{K}^{*}$ are the optimal lot size and the minimum cost rate for the model with incorrect unit stockholding cost rate, $h$. The adjusted unit stockholding cost rate, $\widehat{h}$, and the total fixed cost rate, $\mathfrak{C}$, are evaluated adopting the cost structure given in Table 1 . We also introduce the following measures:

$\mathrm{PE}_{1}=\frac{\widehat{\mathfrak{\Re}}\left(Q^{*}\right)-\widehat{\Re}^{*}}{\widehat{\mathfrak{\Re}}^{*}} \times 100$,

$\mathrm{PE}_{2}=\frac{\widehat{\mathfrak{\Re}}^{*}-\mathfrak{\Re}^{*}}{\mathfrak{\Re}^{*}} \times 100$.

Equation (21) represents the percentage error in the cost rate that results if the incorrect optimal lot, $Q^{*}$, is used instead of the correct optimal lot, $\widehat{Q}^{*}$, in an inventory system 
Table 1 Cost structures including cost differentiation

\begin{tabular}{|c|c|c|c|}
\hline \multicolumn{2}{|l|}{ Cost structure A } & \multicolumn{2}{|l|}{ Cost structure B } \\
\hline Fixed costs & Variable costs & Fixed costs & Variable costs \\
\hline Floor space & Direct labour & Machines & $\begin{array}{l}\text { Product damage/depre- } \\
\text { ciation and deteriora- } \\
\text { tion }\end{array}$ \\
\hline Energy* & Obsolescence & Racks & Lost sales and backlog \\
\hline Cleaning & Product damage & Control system & \\
\hline Surveillance & Product depreciation & Fire protection & \\
\hline Insurances* & $\begin{array}{l}\text { Product deterioration/ } \\
\text { expiration }\end{array}$ & Aisle equipment & \\
\hline Taxes & Stock list execution & $\begin{array}{l}\text { WHMS and HAS equipments } \\
\text { (hardware and software) }\end{array}$ & \\
\hline Material handling/storage equipments & Inspection and counting during the year & Installation and testing & \\
\hline WHMS $^{\mathrm{a}}$ and $\mathrm{HAS}^{\mathrm{b}}$ equipments & Remanufacturing & Training & \\
\hline Maintenance & Repackaging and relabelling & Conveyor systems & \\
\hline \multirow{5}{*}{$\begin{array}{l}\text { Indirect labour and } \\
\text { supervision }\end{array}$} & Lost sales and backlog & Lands and building & \\
\hline & & Indirect labour & \\
\hline & & Supervision & \\
\hline & & Energy* & \\
\hline & & Maintenance & \\
\hline
\end{tabular}

${ }^{\mathrm{a}}$ Warehouse management system

${ }^{\mathrm{b}}$ Handling system

whose operating cost is calculated with the correct procedure. Equation (22) gives the percentage error between the correct optimal cost rate, $\widehat{\mathfrak{\Re}}^{*}$, and the incorrect optimal cost rate, $\mathfrak{\Re}^{*}$. The results of these experiments are shown in Table 2, where $\mathrm{PE}_{1}$ and $\mathrm{PE}_{2}$ are obtained by means of Eqs. (21) and (22), respectively.

The experimental observations confirm the theoretical results discussed in the previous section. We immediately note the significant difference between the correct minimum cost rate and the minimum cost rate corresponding to the incorrect unit stockholding cost rate formulation. This substantial deviation is due to the inadequacy of the traditional cost model in handling fixed warehouse costs. In this regard, it is interesting to compare the columns relevant to $\mathfrak{E}$ and $\mathfrak{K}^{*}$ in Table 2 . We recall that the incorrect optimal cost, $\mathfrak{K}^{*}$, includes ordering and stockholding costs. The stockholding cost component consists, in turn, of fixed and variable warehouse costs. Hence, the difference between $\mathfrak{C}$ and $\mathfrak{K}^{*}$ makes evident that the incorrect cost model considerably underestimates fixed warehouse costs.

To clarify this aspect further, Table 3 shows, for each industrial case, the fixed component of the unit stockholding cost rate used in the incorrect cost model. We denote this cost component by $h_{F}$. Table 3 also shows $h_{F}^{*}=h_{F} Q^{*} / 2$, which is the average stockholding cost rate pertaining to the fixed costs and corresponding to the incorrect optimal lot. To facilitate the comparison, Table 3 includes the fixed cost rate, $\mathfrak{\mathfrak { C }}$. The table illustrates that a substantial difference between $\mathfrak{C}$ and $h_{F}^{*}$ can occur. It thus becomes apparent that the traditional cost model inadequately handles fixed warehouse costs, and that these costs are heavily underestimated.

Given that the traditional methodology includes fixed warehouse costs in the calculation of the unit stockholding cost rate, we observe that $h>\widehat{h}$. This leads to an optimal
Table 2 Results of the numerical experiments

\begin{tabular}{llllllllll}
\hline & $\begin{array}{l}\mathfrak{5} \\
{[€ / \text { year }]}\end{array}$ & $\begin{array}{l}\hat{h} \\
{[€ / \text { unit/year] }]}\end{array}$ & $\begin{array}{l}h \\
{[€ / \text { unit/year }]}\end{array}$ & $\begin{array}{l}\hat{Q}^{*} \\
{[\text { unit] }]}\end{array}$ & $\begin{array}{l}Q^{*} \\
{[\text { unit }]}\end{array}$ & $\begin{array}{l}\widehat{\Re}^{*} \\
{[€ / \text { year }]}\end{array}$ & $\begin{array}{l}\mathfrak{\Re}^{*} \\
{[€ / \text { year }]}\end{array}$ & $\begin{array}{l}\mathrm{PE}_{1} \\
(\%)\end{array}$ & $\begin{array}{l}\mathrm{PE}_{2} \\
\left(\% \times 10^{3}\right)\end{array}$ \\
\hline Case A & $819,100.4$ & 23.84 & 51.00 & 323.8 & 221.4 & $826,820.5$ & $11,291.6$ & 0.68 & 7.22 \\
Case B & $460,569.9$ & 25.18 & 44.70 & 315.1 & 236.5 & $468,504.0$ & $10,571.2$ & 0.70 & 4.33 \\
Case C & $150,100.0$ & 37.64 & 45.54 & 257.7 & 234.3 & $159,800.5$ & $10,670.1$ & 0.28 & 1.40 \\
Case D & $794,467.0$ & 38.40 & 65.94 & 255.2 & 194.7 & $804,265.0$ & $12,839.4$ & 0.45 & 6.16 \\
Case E & $260,407.0$ & 35.16 & 43.98 & 266.7 & 238.4 & $269,782.5$ & $10,485.7$ & 0.22 & 2.47 \\
\hline
\end{tabular}


Table 3 Comparison of the fixed warehouse costs for Cases A to E

\begin{tabular}{lllr}
\hline & $\begin{array}{l}\mathfrak{c} \\
{[€ / \text { year }]}\end{array}$ & $\begin{array}{l}h_{F} \\
{[€ / \text { unit/year }]}\end{array}$ & $\begin{array}{l}h_{F}^{*} \\
{[€ / \text { year] }}\end{array}$ \\
\hline Case A & $819,100.4$ & 27.16 & $3,006.7$ \\
Case B & $460,569.9$ & 19.52 & $2,308.2$ \\
Case C & $150,100.0$ & 7.90 & 925.5 \\
Case D & $794,467.0$ & 27.54 & $2,681.2$ \\
Case E & $260,407.0$ & 8.82 & $1,051.4$ \\
\hline
\end{tabular}

lot size $Q^{*}$ that is smaller than the optimal lot size of the adjusted model, $\hat{Q}^{*}$. We find that the percentage difference between $\widehat{Q}^{*}$ and $Q^{*}$ varies between a minimum of $9.1 \%$ in Case $\mathrm{C}$ and a maximum of $31.6 \%$ in Case A. Because of the specific parameter values adopted in these experiments, and because earlier research has shown that the EOQ model is quite robust to variations around the optimal lot size (Stadtler 2007), the cost impact of using an incorrect lot size is not particularly large: the smallest value observed is $0.22 \%$ (Case E) while the largest one is $0.70 \%$ (Case A). We would like to pinpoint that the specific error values that came up from the experiments are purely indicative, as we had to assume both the value for some parameters and the inventory model. We nevertheless believe that calculating the inventory carrying charges correctly is important in inventory control given the often large numbers of stock keeping units that are held in inventory in practice. Errors that result from an incorrect cost calculation procedure may accumulate and unnecessarily drive up inventory carrying cost.

\section{Conclusions}

This paper provided arguments against an approach traditionally adopted in the literature for establishing the unit stockholding cost rate in the context of average-cost lost sizing models. In particular, we discussed why fixed warehouse costs should not be included in the calculation of inventory carrying charges.

We analytically developed our arguments considering the classical EOQ model and referred ourselves to the methodology proposed by Azzi et al. (2014) to calculate the unit stockholding cost rate, which, in our opinion, is the most comprehensive methodology currently available in the literature, even though it is based on the traditional approach. We then presented numerical experiments to assess the effect of the correct procedure to evaluate the unit stockholding cost rate on inventory decisions. These experiments were performed considering warehouse costs taken from the industrial case studies presented by Azzi et al. (2014). While the impact of incorrectly calculating the inventory carrying costs on the total cost of the lot sizing model may be small (which clearly depends on the specific inventory system parameters and on the inventory control policy), an incorrect calculation procedure has the potential to distort inventory management decisions given the large number of stock keeping units (SKUs) that are held in stock in many companies.

To conclude, our study demonstrated that the traditional cost model does not correctly handle fixed warehouse costs, and, in particular, it heavily underestimates them. Inventory management decisions are consequently distorted, e.g., the company orders more often and/or in smaller quantities than actually required by the true optimal decision. It is thus strongly recommended to not include fixed warehouse costs into inventory carrying charges, because this would lead to suboptimal decisions.

Future researches may be devoted to an in-depth investigation into the impact of incorrectly calculating the unit stockholding cost rate on inventory systems subject to random demand, perhaps considering alternative inventory control policies. In addition, it may be interesting to analyse the distortion resulting from wrong inventory carrying charges in supply chain coordination mechanisms, such as the consignment stock agreement.

Funding Open access funding provided by Università degli Studi di Napoli Federico II within the CRUI-CARE Agreement. No funding was received for conducting this study.

\section{Declarations}

Conflicts of interest The authors have no conflicts of interest to declare that are relevant to the content of this article.

Open Access This article is licensed under a Creative Commons Attribution 4.0 International License, which permits use, sharing, adaptation, distribution and reproduction in any medium or format, as long as you give appropriate credit to the original author(s) and the source, provide a link to the Creative Commons licence, and indicate if changes were made. The images or other third party material in this article are included in the article's Creative Commons licence, unless indicated otherwise in a credit line to the material. If material is not included in the article's Creative Commons licence and your intended use is not permitted by statutory regulation or exceeds the permitted use, you will need to obtain permission directly from the copyright holder. To view a copy of this licence, visit http://creativecommons.org/licenses/by/4.0/.

\section{References}

Adam D (2001) Produktions-Management, 9th edn. Gabler, Wiesbaden Andriolo A, Battini D, Grubbström RW, Persona A, Sgarbossa F (2014) A century of evolution from Harris's basic lot size model: Survey and research agenda. Int J Prod Econ 155:16-38. https://doi.org/ 10.1016/j.ijpe.2014.01.013 
Azzi A, Battini D, Faccio M, Persona A, Sgarbossa F (2014) Inventory holding costs measurement: a multi-case study. Int J Logist Manag 25(1):109-132. https://doi.org/10.1108/IJLM-01-2012-0004

Bogaschewsky R (1996) Losgröße, in: Kern, W.; Schröder, H.-H.; Weber, J. (Ed.): Handwörterbuch der Produktionswirtschaft. 2nd. d., Stuttgart, Schäffer-Poeschel, p. 1141-1158

Buscher U, Daub A, Götze U, Mikus B, Roland F (2010) Produktion und Logistik. Einführung mit Fallbeispielen. 2nd. ed., GUCVerlag, Chemnitz

Glock CH (2014) Produktion und Supply Chain Management. Eine Einführung. B+G Wissenschaftsverlag, Würzburg

Glock CH, Grosse EH, Ries JM (2014) The lot sizing problem: A tertiary study. Int J Prod Econ 155:39-51. https://doi.org/10.1016/j. ijpe.2013.12.009

Grubbström RW (1980) A principle for determining the correct capital costs of work-in-progress and inventory. Int J Prod Res 18(2):259 271. https://doi.org/10.1080/00207548008919665

Grubbström RW, Thorstenson A (1986) Evaluation of capital costs in a multi-level inventory system by means of the annuity stream principle. Eur J Oper Res 24:136-145. https://doi.org/10.1016/ 0377-2217(86)90019-6

Hadley G, Whitin TM (1963) Analysis of inventory systems. PrenticeHall, Englewood Cliffs, NJ

Hahn D, Laßmann G (1999) Produktionswirtschaft - Controlling industrieller Produktion, 3rd edn. Physica-Verlag, Heidelberg

Harris FW (1913) How many parts to make at once. Factory - Mag Manag 10(2), 135-136. https://doi.org/10.1287/opre.38.6.947

Hartmann H (2002) Materialwirtschaft, 8th edn. Deutscher Betriebswirte-Verlag, Gernsbach
Johnson LA, Montgomery DC (1974) Operations research in production planning, scheduling, and inventory control. John Wiley \& Sons, New York

Nahmias S (2013) Production and operations analysis, 6th edn. McGraw-Hill/Irwin, New York, NY

Relph G, Milner C (2015) Inventory management. Advanced methods for managing inventory within business systems, Kogan Page, London

Silver EA, Pyke DF, Thomas DJ (2017) Inventory and production management in supply chains. CRC Press, Boca Raton, FL

Stadtler H (2007) How important is it to get the lot size right? Z Betriebswirt 77(4):407-416. https://doi.org/10.1007/ s11573-007-0031-6

Teunter RH, van der Laan E, Inderfurth K (2000) How to set the holding cost rates in average cost inventory models with reverse logistics? Omega 28:409-415. https://doi.org/10.1016/S0305-0483(99) 00070-5

U.S. Census Bureau (2021) Manufacturing and trade inventories and sales, February 2021, https://www.census.gov/mtis/www/data/ text/timeseries1.xlsx. Accessed on 18 Feb 2021

Waters CDJ (1992) Inventory control and management. John Wiley \& Sons, Chichester

Zipkin PH (2000) Foundations of inventory management. McGrawHill/Irwin, New York, NY

Publisher's Note Springer Nature remains neutral with regard to jurisdictional claims in published maps and institutional affiliations. 